\title{
Surgical angiogenesis for scaphoid non-union: a literature review
}

Jamie Corcoran, 1, a, @ Usama Zafar, 1 Iulian Nusem, 1, 2, 3

@ corresponding author, \& equal contributor

Vascular Cell. 2020; 12(1):1 | ๔ Jamie Corcoran, Usama Zafar, lulian Nusem

Received: 10 October 2019 | Accepted: 11 November 2019| Published: 11 January 2020

Vascular Cell ISSN: 2045-824X

DOI: https://doi.org/10.24238/13221-12-1-187

Author information
1. Department of Orthopaedic Surgery - Logan Hospital; Meadowbrook, QLD 4131, Australia
2. Griffith University; Southport, QLD 4215, Australia
3. Queensland Bone Bank; Coopers Plains, QLD 4108, Australia

[a] corcorjw@tcd.ie

\begin{abstract}
Non-union of scaphoid bone fractures, though an uncommon occurance, are a signficant cause of morbidity in young patients. This review outlines the current understanding of vascularised bone grafts and non-union, and examines the most current clinical literature regarding the role of these procedures in modern orthopaedic practice. Composite evidence from level III studies would support using osseous grafts on a vascular pedicle for patients with non-union of the proximal end of the scaphoid with associated avascular necrosis and in cases of revision surgery where a previous nonvascularised graft has failed to achieve bony union.
\end{abstract}

\section{Keywords}

scaphoid - fracture - non-union - vascularised - angiogenesis - graft - flap

\section{Introduction}

Disturbance of vascular supply to bone forming cells after trauma predisposes to non-union, which is defined as the cessation of periosteal and endosteal histological healing responses before the fracture has healed [1]. Non-union of scaphoid fractures complicates approximately $5-15 \%$ of cases; it causes significant morbidity in adults of working age, typically manifesting as chronic wrist pain, stiffness, and diminished grip strength. If untreated, the natural history of scaphoid nonunion is progression to scaphoid non-union advanced collapse (SNAC), a form of wrist osteoarthritis that often requires salvage procedures such as proximal row carpectomy or wrist arthrodesis to manage $[2,3]$.

Since the 19th century, bone grafts have been the gold standard for reconstruction of osseous defects, including fracture non-unions [4]. In the realm of tissue engineering, bone grafts should possess some, and ideally all, of the following three key properties, in order to enhance bony union: osteoconduction, osteoinduction, and osteogenesis. Osteoconduction refers to the presence of a scaffold that enhances cellular interactions and fosters formation of bone extracellular matrix; osteoinduction pertains to the presence of growth factors that stimulate proliferation and differentation of osteogenic cells, such as bone morphogenetic protein; osteogenesis involves mesenchymal osteoprogenitor cells that can differentiate into mature osteoblasts, osteoclasts, and osteocytes [5].

Bone grafts with a vascular pedicle, such as the free fibula flap described in 1974, have been used to great success in orthopaedic, plastic and reconstructive, and maxillofacial disciplines by creating surgical angiogenesis. Local pedicled bone flaps for scaphoid non-union were first described in 1965 by Roy-Camille et al, and since then have been the workhorse of difficult scaphoid non-unions [3]. The sine qua non of vascularised grafts is that they provide a continuous supply of essential nutrients to the fracture site, as well as living osteoprogenitor cells, i.e. they possess osteogenic potential, unlike non-vascularised grafts.

Principles of managing scaphoid fractures involve 
correcting the deformity, providing stability with internal fixation, and ensuring viability and vascularity; when these are employed correctly, union rates of approximately $90 \%$ can be expected; however the scaphoid has a peculiar intraosseous retrograde blood supply, which puts it at risk of non-union and avascular necrosis; higher risk with displaced and more proximal fractures $[6,7,8]$. Several anatomical studies have demonstrated that
$70-80 \%$ of the scaphoid, including the entire proximal pole, is supplied retrogradely by the dorsal carpal branches of the radial artery, which enter the dorsal ridge osseous foramina; the remaining $20-30 \%$ of the mostly distal scaphoid receives arterial supply from volar carpal branches of the radial artery $[9,10,11]$, with minor collateral supply from the anterior interosseous artery.

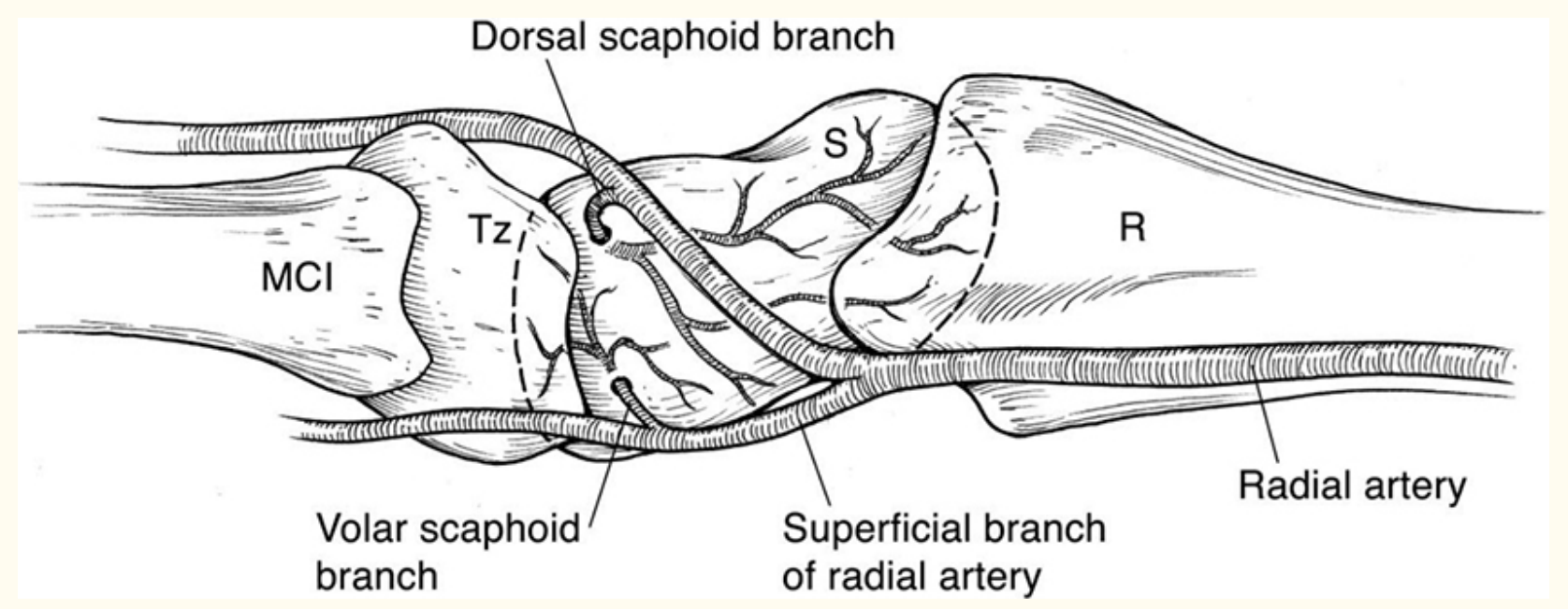

Figure 1

\section{Figure 1}

Extra-osseous vascular anatomy of the scaphoid from [11]. $\mathrm{R}=$ radius, $\mathrm{S}=$ scaphoid, Tz $=$ trapezium, $\mathrm{MCl}=$ first metacarpal.

Key steps in the management of a scaphoid nonunion are correcting any intra-scaphoid deformity, such as the humpback deformity, re-aligning the kinematics of the proximal carpal row, and achieving bony union of the scaphoid using internal fixation and osseous graft [12].

Although more challenging from a surgical perspective, many experimental and clinical studies have shown that scaphoid bone grafts on a vascularised pedicle possess several clinical benefits over standard and more popular nonvascularised grafts, such as the Matti-Russe inlay graft and the Fisk-Fernandez wedge graft, due to faster and higher rates of bony union, as well as higher upper limb functional scores $[\underline{7}, 13,14,15]$. However, non-vascularised grafts still remain the

\section{Anatomy of vascularised grafts}

The afferent arterial flow to bone comes from both inner endosteal and outer periosteal vessel systems, venous drainage following a similar pattern. Overall flow is usually centrifugal, from standard of care in most centres due to their relative ease and satisfactory results in most cases, with union rates of $40-90 \%$ having been described in the literature []].

Although indications are controversial, vascularised grafts are generally indicated for non-unions associated with compromised proximal pole vascularity, i.e. avascular necrosis, and revision surgery, where a non-vascularised graft has been unsuccessful $[\underline{3}, \underline{6}, \underline{16}, \underline{17}, \underline{18}]$. Proximal pole vascularity is typically assessed intra-operatively by probing for punctate bleeding; pre-operative imaging using MRI is not always reliable $[\underline{6}, \underline{19}]$.

endosteum to periosteum via capillaries in Haversian and Volkmann canals, largely due to pressure gradient and external muscular pump forces. In general, 3 systems of arteries supply bones in the limbs; these are nutrient vessel (NV), Penetrating Periosteal Vessel (PPV), and Non- 
Penetrating Periosteal Vessel (NPPV) [4].

NV is the typical endosteal supply, supplying cancellous bone and $50-70 \%$ of inner cortical bone of diaphysis and metaphysis. En bloc bone grafts, such as fibula and rib, require their NV to survive.

PPV is typical of epiphysis and metaphysis, being an end artery to the endosteal surface; typically will only support a unicortical/corticocancellous flap.
NPPV is typical of diaphyseal bone, coming directly from a named vessel that doesn't traverse muscle, or via a muscular or deep fascial artery. It does not extend to endosteal surface, unlike PPV. NPPV generally supplies the periosteum and outer $30 \%$ of the cortex, thus only cortical bone can be reliably harvested during grafting; cancellous bone is typically not supported by the NPPV.

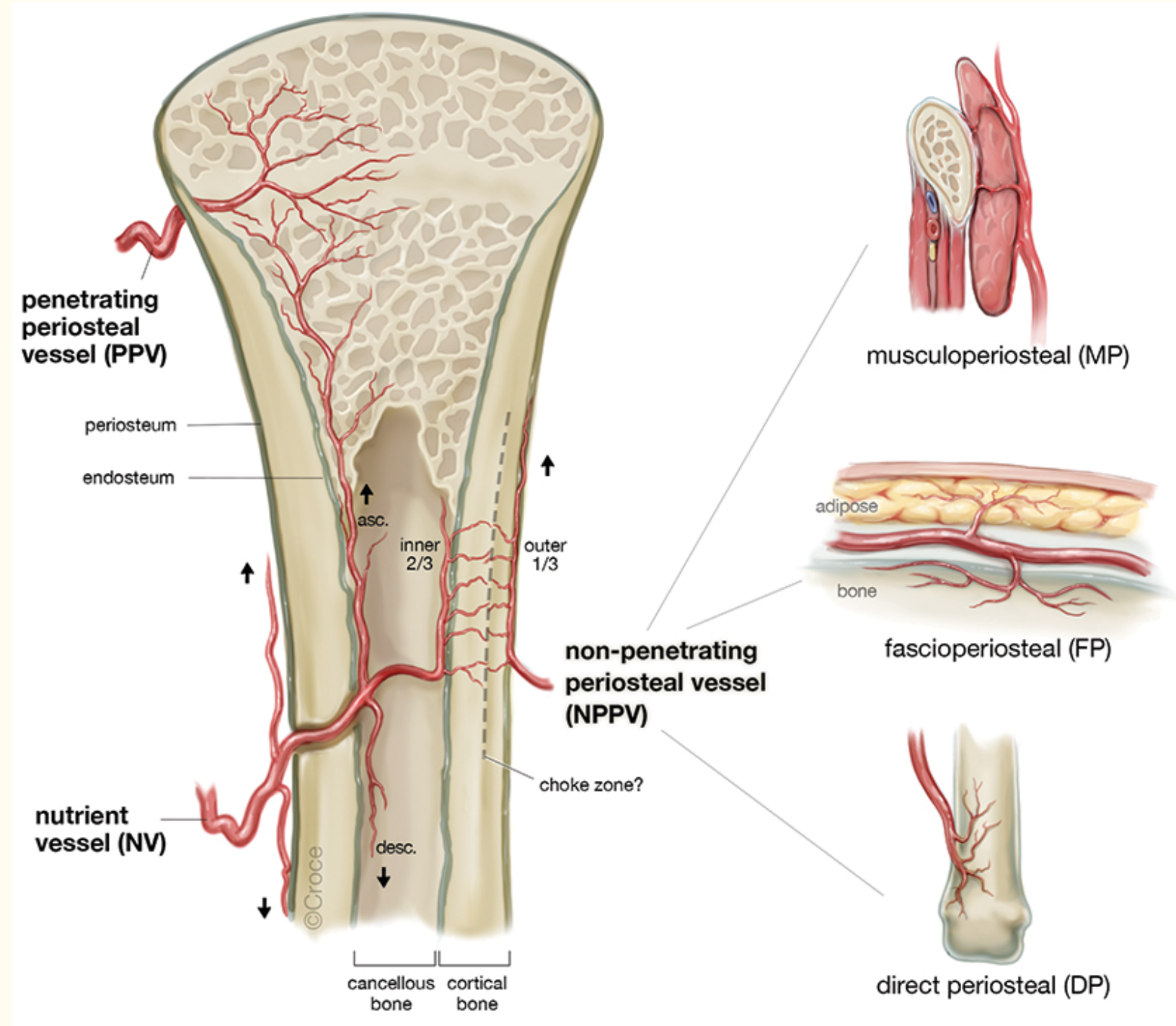

Figure 2

\section{Figure 2}

Systems of osseous vascularity, from [4]

Vascularised bone grafts can be categorised in multiple ways [13]. The two most useful ways to classify them for this discussion are based on their pattern of osseous vascularity, i.e. NV, PPV, NPPV; and the need for surgical anastomosis, e.g. local pedicled flaps or free flaps. 


\section{Table 1}

\section{Commonly utilised vascularised bone grafts for scaphoid non-union}

\section{LOCAL PEDICLED FLAPS}

\begin{tabular}{|c|c|c|}
\hline Source & Pedicle vessel & Type of vessel \\
\hline Dorsal radius & 1,2 - intercompartmental supraretinacular artery & $\begin{array}{l}\text { NPPV (direct } \\
\text { periosteal) }\end{array}$ \\
\hline Dorsal radius & 2,3 - intercompartmental supraretinacular artery & $\begin{array}{l}\text { NPPV (direct } \\
\text { periosteal) }\end{array}$ \\
\hline Volar radius & Anterior transverse carpal artery & PPV \\
\hline Dorsal radius & $4^{\text {th }}$ extensor compartment artery & $\begin{array}{l}\text { NPPV (direct } \\
\text { periosteal) }\end{array}$ \\
\hline Dorsal radius & $4^{\text {th }} / 5^{\text {th }}$ extensor compartment artery & $\begin{array}{l}\text { NPPV (direct } \\
\text { periosteal) }\end{array}$ \\
\hline Volar radius & $\begin{array}{l}\text { Pronator quadratus pedicled flap (anterior interosseous } \\
\text { artery) }\end{array}$ & $\begin{array}{l}\text { NPPV } \\
\text { (musculoperiosteal) }\end{array}$ \\
\hline Metacarpal & Dorsal metacarpal artery & $\begin{array}{l}\text { NPPV (direct } \\
\text { periosteal) }\end{array}$ \\
\hline Ulna & FCU artery & $\begin{array}{l}\text { NPPV (direct } \\
\text { periosteal) }\end{array}$ \\
\hline \multicolumn{3}{|c|}{ LOCAL PEDICLED FLAPS } \\
\hline Source & Pedicle vessel & Type of vessel \\
\hline Iliac crest & Deep circumflex iliac artery & PPV \\
\hline $\begin{array}{l}\text { Medial femoral } \\
\text { condyle }\end{array}$ & Descending genicular artery & PPV \\
\hline
\end{tabular}




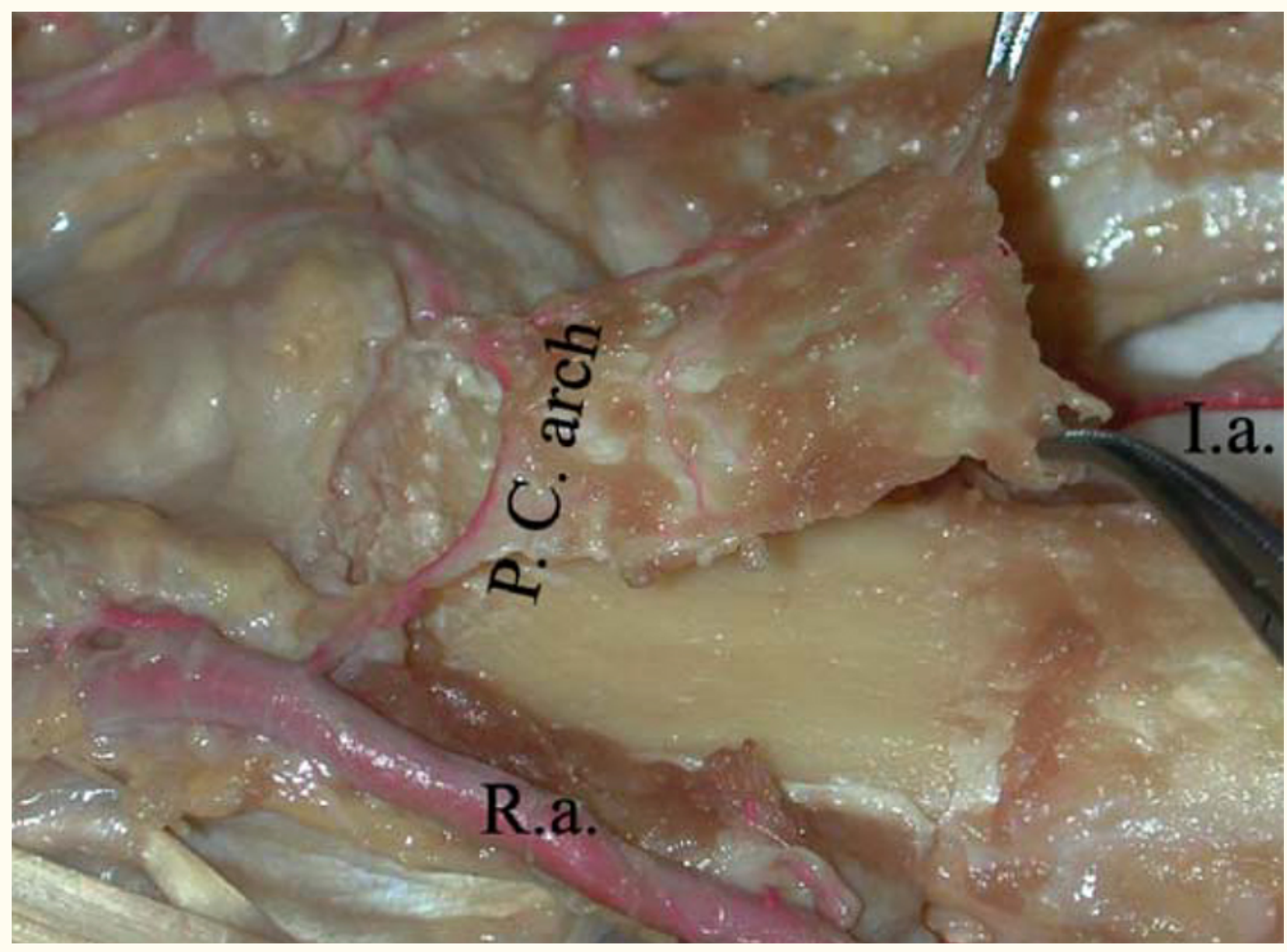

Figure 3

Figure 3

Anterior transverse carpal artery graft from volar distal radius, from [13]

The best described and most commonly utilised vascularised bone graft is that described by Carlos Zaidemberg in 1991; a segment of cortical bone from the dorsum of the radial styloid supplied by the 1,2 - intercompartmental supraretinacular artery [20].

From a technique point of view, dorsal radius flaps are more difficult to use for waist non-unions due to risk of kinking the pedicle, i.e. volar radius or free flaps are more suitable [13]. The pattern of arterial supply for most vascularised scaphoid grafts is NPPV, hence may not be sufficient to supply the

\section{Angiogenesis and non-union}

Fracture healing at a molecular level, requires a symphony of growth factors, both temporally and spatially, in order to turn the initial haematoma into callus and finally mature bone.

Angiogenesis is an early, and critical process in entire flap, especially if deeper cortex or cancellous bone is harvested.

Despite the difficulty of performing vascularised bone grafts and the small calibre of NPPVs, a recent Magnetic Resonance Angiography study has demonstrated post-operative patency and functionality of the most commonly used vascularised scaphoid graft, the 1,2 intercompartmental supraretinacular artery in 13 out of 14 patients [21]

fracture healing, a fact that has been known since the 18th century [22]. Chondroclasts release proangiogenic growth factors which stimulate vessels to grow and penetrate the cartilagenous soft callus. New vessels allow influx of oxygen, nutrients, and various stem cells for osteogenesis. 
Angiogenesis is largely mediated by the transcription factor Hypoxia Inducible Factor- $1 \alpha$ (HIF-1 $\alpha)$, Vascular Endothelial Growth Factor (VEGF) and thrombin, which are highly concentrated in the initial fracture haematoma [23]. Bone morphogenetic proteins are also critical growth factors for fracture healing, stimulating bone formation and angiogenesis, being involved in positive feedback loop with VEGF [24].

Interestingly, following bone grafting, serum VEGF levels have been shown to be higher in the early post-operative period, i.e. the first four weeks, in vascularised vs non-vascularised bone grafts [25]

VEGF is also important in later stages of fracture healing, namely woven bone resorption and remodelling into lamellar bone, via stimulation of osteoclasts. In addition, VEGF has been shown to stimulate healing in early fractures and established non-union in animal models $[26,27,28]$.

However, a study involving femoral osteotomies in mice showed that establishment of non-union has less association with VEGF and early angiogenesis;

\section{Recent clinical evidence}

Conventional wisdom would say that using a nonvascularised graft for proximal pole non-union may risk failure: a 2002 review of 36 studies by Merrell et al. reported a $47 \%$ union rate for this group of patients, versus $88 \%$ for those patients treated with vascularised grafts [17]. Contrary to these findings evidence from a large 2015 systematic review and various cohort studies comparing vascularised and non-vascularised grafts shows broadly similar outcomes $[7,35,36,37]$. More recently, two studies published in 2018 by Luchetti et al and Kim et al $[38,39]$ showed promising results. These are both case series of a combined 44 patients with proximal pole non-unions, managed using non-vascularised grafts, wherein union rates of $90 \%$ were achieved. The first study assessed union but not proximal pole vascularity, and the second study excluded patients with "significant proximal pole fragmentation". Although both studies have intriguing findings, they are level 4 evidence, obviously limiting their external validity, but hopefully inspiring further evaluation of the use of non-vascularised grafts in the setting of proximal pole non-unions.

Accurate comparision between vascularised and non-vascularised grafts is challenging due to their differing indications and demographics - patients requiring vascularised grafts usually have more diseased scaphoids, i.e. the presence of AVN or persistent non-union; thus it may be reasonable to argue that vascularised grafts are superior, as similar outcomes are seen, despite compromised bone.

Studies comparing different vascularised flaps are more numerous in the literature. A meta-analysis published in 2017 by Ditsios et al. [16] analysed nine different osseous flaps across over 1000 patients. Statistically, the flaps with the highest instead has more to do with lower levels of osteogenic growth factors BMP-2 and BMP-4 [29]. In fact, several studies have shown higher serum levels of VEGF in non-union $[29,30,31]$.

The histological features seen in the fracture gap can give an estimation of healing potential. Features of vitality include high cellular density, presence of vessels, unmineralised osteoid formation and formation of trabecular spikes lined by osteoblasts. Features that suggest poor healing potential include fibrous tissue in the gap, cartilaginous tissue in the fracture gap, sclerotic closure/seal, formation of bone cysts, presence of TRAP-positive cells, i.e. osteoclasts, and loss of trabecular structure. Many studies have shown that healing capacity of the distal scaphoid fragment reduces with time $[2,32,33]$, whereas some studies $[2,34]$ have shown that the proximal fragment's healing capacity is not time-dependent; it is at low level from early stages due to compromised vascularity; these time-dependent histological changes may support the utilisation of vascularised grafts for the older non-unions.

union rates were the medial femoral condyle, pronator quadratus, and 2nd metacarpal flaps, demonstrating union rates of $100 \%, 96.7 \%$, and $94.9 \%$ respectively. Non-unions with associated proximal pole AVN showed a similar trend, with slightly lower union rates. The higher union rates of femoral and pronator quadratus flaps may be explained by the fact that they are based on PPV and musculoperiosteal pedicles respectively, which have a larger arterial calibre than the NPPVs typical of most scaphoid flaps.

Due to different Patient-Reported Outcome Measures (PROMs) being used in different studies, unified scores had to be utilised to allow direct comparision; which necessarily involves an element of confounding bias. The pronator quadratus and volar radius flaps had the best grip strength and functional outcome scores in this meta-analysis. The most commonly utilised flap was the dorsal distal radius flap based on the 1,2 intercompartmental supraretinacular artery, i.e. the aforementioned Zaidemberg flap; it had a union rate of $83 \%$. Despite being a respectable rate of bony union, this was actually the lowest union rate of all flaps in the meta-analysis, and the functional scores were inferior to most of the other flaps; however being by far the most commonly used flap, this finding is not entirely unexpected. Due to the quality of many of the studies included in the metaanalysis, significant bias is present, and any conclusions that can be drawn from them are thereby limited.

A systematic review performed in 2017 by Alluri et al. [3] involving vascularised grafts in over 1000 patients showed a $84.7 \%$ union rate and $91 \%$ satisfaction rate. $85 \%$ of these were the classic Zaidemberg flap. Although the free grafts were associated with an $11 \%$ higher union rate compared 
to the pedicled grafts, there was no statistical difference in this regard. A greater post-operative range of motion was demonstrated with the local flaps. This review also found statistically similar union rates for non-unions in both waist and proximal pole regions. Also, it reassuringly demonstrated similar outcomes for vascularised grafts done as a primary or revision procedure.

\section{Conclusion}

Scaphoid non-union is a complex problem facing hand surgeons in modern clinical practice. The use of osseous grafting is a key element in a surgeon's armamentarium to increase the chance of bony healing, via implantation of osteoconductive, osteoinductive, osteogenic tissue. Using tissue that still possesses its own native vascularity theoretically enhances this further.

Literature would suggest that using nonvascularised graft is appropriate for surgical managment in all scaphoid non-unions, except those with evidence of proximal pole avascular necrosis, despite recent studies [38,39] suggesting otherwise, i.e. $90 \%$ union rates using nonvascularised graft. These studies had limitations; both were level 4 evidence studies with few patients and did not assess proximal pole vitality. Although controversial, current evidence-based consensus would suggest that the promotion of angiogenesis via vascularised grafting should be reserved for situations of non-union associated with avascularity of the proximal pole and in revision

\section{Copyright permissions}

The image copyright permissions are solely the responsibility of the authors.

Image copyright permissions have been obtained for the following media:

\section{Original submitted files for images}

Below are the links to the authors' original submitted files for images.

Original image file for Figure 1

Click here to view.

\section{References}

1. Marsh D. Concepts of fracture union, delayed union, and nonunion. Clin Orthop Relat Res. 1998;(355 Suppl):S22-30.

2. Schmidle G, Ebner HL, Klima G, Pfaller K, Fritz J, Hoermann $\mathrm{R}$, et al. Time-dependent changes in bone healing capacity of scaphoid fractures and non-unions. J Anat. 2018;232(6):908-18.
Both of these large reviews are mostly based on level 3 evidence / retrospective cohort studies, which limits their utility due to considerable bias. Since this large meta-analysis and systematic review, other studies have demonstrated similar union rates $[8,40,41,42,43]$.

surgery, where a non-vascularised graft has failed to create bony union.

Regarding vascularised grafts themselves, the current evidence base would suggest that grafts based on a larger pedicled vessel yield higher scaphoid union rates, namely those based on musculoperiosteal vessels or penetrating periosteal vessels, for instance the medial femoral condyle graft and the pronator quadratus graft.

As is typical with clinical studies of uncommon and rare occurances, such as scaphoid non-union, much of the literature involves retrospective cohort studies, often accompanied with considerable confounding bias. In the future, large multicentre randomised controlled trials comparing different types of vascularised and non-vascularised grafts for waist and proximal pole non-unions, with and without avascular necrosis is warranted to help clinicians determine which patients will benefit most from surgical angiogenesis in the setting of this debilitating condition.

- Figure 1: license content publisher Wolters Kluwer Health, Inc., license no. 4732120045936.

- Figure 2: license content owner Beth Croce and Bioperspective.

- Figure 3: license content publisher Elsevier, license no. 4732110967765.

Original image file for Figure 2

Click here to view.

Original image file for Figure 3

Click here to view.
3. Alluri RK, Yin C, lorio ML, Leland H, Mack WJ, Patel K. A Critical Appraisal of Vascularized Bone Grafting for Scaphoid Nonunion. J Wrist Surg. 2017;6(3):251-7.

4. Sparks DS, Saleh DB, Rozen WM, Hutmacher DW, Schuetz MA, Wagels M. Vascularised bone transfer: History, blood supply and contemporary 
problems. J Plast Reconstr Aesthet

Surg. 2017;70(1):1-11.

5. Khan WS, Rayan F, Dhinsa BS, Marsh D. An osteoconductive, osteoinductive, and osteogenic tissue-engineered product for trauma and orthopaedic surgery: how far are we?. Stem Cells Int. 2012;2012:236231-.

6. Ng AW, Griffith JF, Taljanovic MS, Li A, Tse WL, Ho PC. Is dynamic contrast-enhanced MRI useful for assessing proximal fragment vascularity in scaphoid fracture delayed and non-union?. Skeletal Radiol. 2013;42(7):983-92.

7. Hirche $C$, Xiong L, Heffinger $C$, Munzberg $M$, Fischer S, Kneser U, et al. Vascularized versus non-vascularized bone grafts in the treatment of scaphoid non-union. J Orthop Surg (Hong Kong). 2017;25(1):2309499016684291-.

8. Rahimnia A, Rahimnia $\mathrm{AH}$, Mobasher-Jannat A. Clinical and functional outcomes of vascularized bone graft in the treatment of scaphoid non-union. PLoS One. 2018;13(5):e0197768-.

9. Gelberman $\mathrm{RH}$, Menon J. The vascularity of the scaphoid bone. J Hand Surg Am. 1980;5(5):508-13.

10. Taleisnik J, Kelly PJ. The extraosseous and intraosseous blood supply of the scaphoid bone. J Bone Joint Surg Am. 1966;48(6):1125-37.

11. Trumble TE, Salas $P$, Barthel T, Robert KQ 3rd. Management of scaphoid nonunions. J Am Acad Orthop Surg. 2003;11(6):380-91.

12. Kalb KH, Langer M, Windolf J, van Schoonhoven J, Pillukat T. Scaphoid pseudarthrosis : Complex reconstruction using vascularized bone grafts. Unfallchirurg. 2019.

13. Soucacos PN, Dailiana Z, Beris AE, Johnson EO. Vascularised bone grafts for the management of non-union. Injury. 2006;37 (Suppl 1):S41-50.

14. Ribak S, Medina CE, Mattar R Jr., Ulson HJ, Ulson HJ, Etchebehere M. Treatment of scaphoid 26. nonunion with vascularised and nonvascularised dorsal bone grafting from the distal radius. Int Orthop. 2010;34(5):683-8.

15. Tanner C, Johnson T, Majors A, Hentz VR, Husak L, Walker Gallego E, et al. The Vascularity and Osteogenesis of a Vascularized Flap for the Treatment of Scaphoid Nonunion: The Pedicle Volar Distal Radial Periosteal Flap. Hand (N Y). 2018.1558944717751191

16. Ditsios K, Konstantinidis I, Agas K, Christodoulou A. Comparative meta-analysis on the various vascularized bone flaps used for the treatment of scaphoid nonunion. Journal of orthopaedic research : official publication of the Orthopaedic Research

Society. 2017;35(5):1076-85.

17. Merrell GA, Wolfe SW, Slade JF 3rd. Treatment of scaphoid nonunions: quantitative meta-analysis of the literature. J Hand Surg Am. 2002;27(4):685-91.
18. Gabl M, Reinhart C, Lutz M, Bodner G, Rudisch A, Hussl $H$, et al. Vascularized bone graft from the iliac crest for the treatment of nonunion of the proximal part of the scaphoid with an avascular fragment. J Bone Joint Surg

Am. 1999;81(10):1414-28.

19. Gunal I, Ozcelik A, Gokturk E, Ada S, Demirtas M. Correlation of magnetic resonance imaging and intraoperative punctate bleeding to assess the vascularity of scaphoid nonunion. Archives of orthopaedic and trauma surgery. 1999;119(5-6):285-7.

20. Zaidemberg C, Siebert JW, Angrigiani C. A new vascularized bone graft for scaphoid nonunion. J Hand Surg Am. 1991;16(3):474-8.

21. Antoniou IK, Athanaselis ED, Rountas C, Koutalos A, Dailiana Z, Malizos KN, et al. MR angiogram confirms sustained blood flow in 1,2 ICSR artery of vascularized bone grafting in scaphoid nonunion treatment. Eur J Orthop Surg Traumatol. 2019;29(2):343-8.

22. Carano RA, Filvaroff EH. Angiogenesis and bone repair. Drug discovery today. 2003;8(21):980-9.

23. Beamer B, Hettrich C, Lane J. Vascular endothelial growth factor: an essential component of angiogenesis and fracture healing. HSS J. 2010;6(1):85-94

24. Deckers MM, van Bezooijen RL, van der Horst G, Hoogendam J, van Der Bent C, Papapoulos SE, et al. Bone morphogenetic proteins stimulate angiogenesis through osteoblast-derived vascular endothelial growth factor $A$.

Endocrinology. 2002;143(4):1545-53.

25. Wang $X$, Wang $C$. Expression of vascular endothelial growth factor in repairing bone defect with vascularized bone graft- reconstituted bone xenograft. Zhongguo Xiu Fu Chong Jian Wai Ke Za Zhi. 2005;19(6):435-8.

26. Eckardt $H$, Ding $M$, Lind $M$, Hansen ES, Christensen KS, Hvid I. Recombinant human vascular endothelial growth factor enhances bone healing in an experimental nonunion model. J Bone Joint Surg Br. 2005;87(10):1434-8.

27. Ogilvie CM, Lu C, Marcucio R, Lee M, Thompson Z, Hu D, et al. Vascular endothelial growth factor improves bone repair in a murine nonunion model. lowa Orthop J. 2012;32:90-4.

28. Zhao DM, Yang JF, Wu SQ, Qiu LP, Liu JL, Wang HB, et al. Effect of vascular endothelial growth factor 165 gene transfection on repair of bone defect: experiment with rabbits. Zhonghua Yi Xue Za Zhi. 2007;87(25):1778-82.

29. Garcia P, Pieruschka A, Klein M, Tami A, Histing T, Holstein $\mathrm{JH}$, et al. Temporal and spatial vascularization patterns of unions and nonunions: role of vascular endothelial growth factor and bone morphogenetic proteins. J Bone Joint Surg Am. 2012;94(1):49-58. 
30. Weiss S, Zimmermann G, Pufe T, Varoga D, Henle $P$. The systemic angiogenic response during bone healing. Archives of orthopaedic and trauma surgery. 2009;129(7):989-97.

31. Sarahrudi K, Thomas A, Braunsteiner T, Wolf $H$, Vecsei V, Aharinejad S. VEGF serum concentrations in patients with long bone fractures: a comparison between impaired and normal fracture healing. Journal of orthopaedic research : official publication of the Orthopaedic Research Society. 2009;27(10):1293-7.

32. Schuind $F$, Haentjens $P$, Van Innis $F$, Vander Maren C, Garcia-Elias M, Sennwald G. Prognostic factors in the treatment of carpal scaphoid nonunions. J Hand Surg Am. 1999;24(4):761-76.

33. Rein S, Hanisch U, Rammelt S, Schmidt G, Schaller HE, Zwipp H, et al. Histopathological, radiological and clinical aspects of the temporal assignment of scaphoid non-union. Archives of orthopaedic and trauma surgery. 2010;130(10):1243-50.

34. Boyer MI, von Schroeder HP, Axelrod TS. Scaphoid nonunion with avascular necrosis of the proximal pole. Treatment with a vascularized bone graft from the dorsum of the distal radius. J Hand Surg 42 Br. 1998;23(5):686-90.

35. Braga-Silva J, Peruchi FM, Moschen GM, Gehlen D, Padoin AV. A comparison of the use of distal radius vascularised bone graft and nonvascularised iliac crest bone graft in the treatmenњ3. of non-union of scaphoid fractures. J Hand Surg Eur Vol. 2008;33(5):636-40.

36. Bao $Y$, Kang H, Zhang ZY, Nie MB, Guo FJ. Treatment of scaphoid nonunion: pedicled vascularized bone graft vs. traditional bone graft. J
Huazhong Univ Sci Technolog Med Sci. 2013;33(5):713-6.

37. Treatment of Scaphoid Nonunion: A Systematic Review of the Existing Evidence. J Hand Surg Am. 2015;40(9):1797-805 e3.

38. Luchetti TJ, Rao AJ, Fernandez JJ, Cohen MS, Wysocki RW. Fixation of proximal pole scaphoid nonunion with non-vascularized cancellous autograft. J Hand Surg Eur Vol. 2018;43(1):66-72.

39. Kim J, Park JW, Chung J, Jeong Bae K, Gong HS, Baek GH. Non-vascularized iliac bone grafting for scaphoid nonunion with avascular necrosis. J Hand Surg Eur Vol. 2018;43(1):24-31.

40. Pulos N, Kollitz KM, Bishop AT, Shin AY. Free Vascularized Medial Femoral Condyle Bone Graft After Failed Scaphoid Nonunion Surgery. J Bone Joint Surg Am. 2018;100(16):1379-86.

41. Morris MS, Zhu AF, Ozer K, Lawton JN. Proximal Pole Scaphoid Nonunion Reconstruction With 1,2 Intercompartmental Supraretinacular Artery Vascularized Graft and Compression Screw Fixation. J Hand Surg Am. 2018;43(8):770 e1-e8.

Kollitz KM, Pulos N, Bishop AT, Shin AY. Primary medial femoral condyle vascularized bone graft for scaphoid nonunions with carpal collapse and proximal pole avascular necrosis. J Hand Surg Eur Vol. 2018.1753193418789329

Malizos KN, Dailiana Z, Varitimidis S, Koutalos A. Management of scaphoid nonunions with vascularized bone grafts from the distal radius: mid- to long-term follow-up. Eur J Orthop Surg Traumatol. 2017;27(1):33-9.

\section{Copyright \& License}

Statement: Copyright (c) 2019, Jamie Corcoran, Usama Zafar, Iulian Nusem. Holder: Jamie Corcoran, Usama Zafar, Iulian Nusem Licensee: Publiverse Online S.R.L.

License: Open Access This article is distributed under the terms of the Creative Commons Attribution 4.0 International License (https://creativecommons.org/licenses/by/4.0/), which permits unrestricted use, distribution, and reproduction in any medium, provided you give appropriate credit to the original author(s) and the source, provide a link to the Creative Commons license, and indicate if changes were made. The Creative Commons Public Domain Dedication waiver (https://creativecommons.org/ publicdomain/zero/1.0/) applies to the data made available in this article, unless otherwise stated.

\section{Vascularcell P7PUBLIVERSE}

The present article has been published in Vascular Cell journal by Publiverse Online S.R.L. 